\title{
Energy Implications in the Single-Vendor Single-Buyer Integrated Production Inventory Model
}

\author{
Simone Zanoni ${ }^{1}$, Laura Bettoni ${ }^{1}$, and Christoph H. Glock ${ }^{2}$ \\ ${ }^{1}$ Department of Mechanical and Industrial Engineering \\ Università degli Studi di Brescia, Via Branze, 38, I-25123, Brescia, Italy \\ \{simone.zanoni, laura.bettoni\} @ing.unibs.it \\ ${ }^{2}$ Carlo and Karin Giersch Endowed Chair "Business Management: Industrial Management", \\ Technische Universität Darmstadt, Hochschulstr. 1, 64289 Darmstadt, Germany \\ glock@bwl . tu-darmstadt.de
}

\begin{abstract}
Increasing energy efficiency is one of the main objectives of the Directive 2009/28/EC of the European Commission (called 20-20-20), which aims at decreasing greenhouse gas emissions by jointly increasing the use of renewable energy and improving energy efficiency, all by $20 \%$ until 2020 . To reduce energy consumption in producing and distributing products, it is of major importance to consider energy consumption in the whole supply chain and for all activities associated with production and distribution. For this reason, this paper studies a single-vendor single-buyer integrated productioninventory system and explicitly takes account of energy consumption. The use of energy is weighted with a cost factor and evaluated together with classical production-inventory costs. We find that if energy costs are considered together with traditional cost components, then the inventory costs of the system increase slightly in the optimum, but the total costs of the system decrease and we observe great energy savings.
\end{abstract}

Keywords: JELS, joint economic lot size model, energy efficiency, energy consumption, single-vendor single-buyer, lot sizing.

\section{Introduction}

Reducing energy consumption is an important measure for firms to lower costs and increase competitiveness, especially in energy-intensive sectors. In trying to reduce the use of energy in industry, a coordinated approach of multiple stages of the supply chain is more promising than individual, uncoordinated actions taken by the members of the chain.

The benefits of coordinated production and replenishment decisions have frequently been studied in the past. So-called joint economic lot size models [1] extend the classical EOQ model to take account of additional cost factors, such as the costs of backorders and lost sales or quality-related costs. Costs associated with the use of energy have, to the best of the authors' knowledge, not been considered in supply chain models before, apart from a preliminary investigation reported in [2]. 
In many industries, energy is one of the most important resources. Preserving energy is the best way to ensure a reliable and sustainable energy supply and to reduce greenhouse gas emissions. Energy can be saved by introducing higher levels of energy efficiency throughout the supply chain, which includes the generation of energy, its transmission and distribution as well as an efficient end use.

This work aims at integrating the use of energy in the classical productioninventory costs of a single-vendor single-buyer supply chain. The intention is to investigate the behavior of the main decision variables in the presence of energy costs. The developed model helps managers in the tactical decision for how to coordinate production, distribution and storage in a supply chain to meet economic and environmental (strictly linked to the total energy spent) targets.

\section{The System}

This study considers an integrated production and inventory system with a singlevendor and a single-buyer, as illustrated in Figure 1.

In this paper, we assume that energy consumption in the supply chain can be influenced by changing the production rates of the vendor and by determining the size of the warehouses used at both parties. Both decisions influence the use of energy in the supply chain by determining how much energy the machines of the vendor require for processing a product, and how much energy is used for operating the warehouse. The use of energy in production has been studied by [3], who showed that different production rates result in different levels of energy consumption. In warehousing, especially for products that need particular conditions for proper storage (e.g. food or perishable items), the dimensions of a warehouse directly impact the use of energy, e.g. due to the need to light or cool the facility [4]. Thus, the consumption of energy is influenced by the lot size decision, and it can be weighted with a cost factor and added to the traditional production-inventory costs.

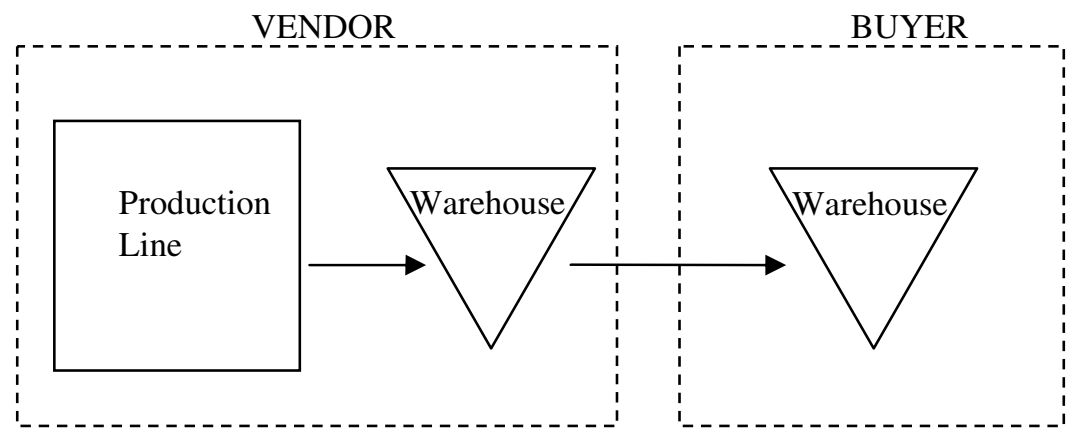

Fig. 1. System considered in the analysis

The following notation will be used throughout the paper:

$A_{l}$ : setup cost of the vendor [€/lot] 

$A_{2}$ : order cost of the buyer [€/order]
$h_{1}$ : inventory holding cost of the vendor [€/unit/time unit]
$h_{2}$ : inventory holding cost of the buyer [€/unit/time unit]
$p$ : production rate [unit/time unit]
$D$ : demand rate[unit/time unit]
$n$ : number of shipments per production lot [delivery/lot]
$q$ : quantity transported per delivery [unit/delivery]

$q_{\max , v}:$ maximum level of stock of the vendor that can be kept, which is subject to the dimensions of the warehouse

$q_{\max , b}$ : maximum level of stock of the buyer that can be kept, which is subject to the dimensions of the warehouse

$Q:$ lot size [unit/lot] $=n \cdot q$

$e$ : energy cost $[€ / \mathrm{kWh}]$

$a, b$ : coefficients that depend on the specific production system (machine) of the vendor

$\alpha, \beta$ : coefficients that depend on the vendor's warehouse characteristics

$\gamma, \delta$ : coefficients that depend on the buyer's warehouse characteristics

$\operatorname{Tr} C$ : traditional total cost (cost per time unit [€/time unit], a function of $n$ and $q$ )

$E C$ : energy costs (cost per time unit [€/time unit], a function of $n$ and $q$ )

$T C$ : total costs considering $(T C=\operatorname{Tr} C+E C)$.

Moreover, we assume that $p>D$, i.e. the production rate is higher than the demand rate and stock-outs or shortages are not allowed.

\section{Model}

In the following, we develop a model that considers the total costs of producing and distributing a product in a single-vendor single-buyer supply chain and that explicitly takes account of energy costs. We then compare the traditional single-vendor singlebuyer system to the system that takes account of energy consumption. The total costs of the traditional single-vendor single-buyer system are formulated as the sum of setup costs, order costs and inventory holding costs for the vendor and the buyer.

In the traditional model, the total inventory costs $(\operatorname{Tr} C(q, n))$ are a function of the lot size and the number of shipments, and they are calculated as follows [5].

$$
\operatorname{Tr} C(q, n)=\left(A_{1}+n \cdot A_{2}\right) \cdot \frac{D}{n \cdot q}+h_{1} \cdot\left(\frac{D \cdot q}{p}+\frac{(p-D) \cdot n \cdot q}{2 \cdot p}\right)+\left(h_{2}-h_{1}\right) \cdot \frac{q}{2} .
$$

Energy costs are formulated as the sum of energy costs during production at the vendor and energy costs caused by storing the products in warehouses at the vendor and the buyer.

As was shown by [3], energy consumption during production can be divided into fixed energy consumption (costs), which is independent of the production rate, and variable consumption (costs). Fixed energy costs are caused by auxiliary tools of 
machines which are switched on during standby and which consume energy although the machine is not producing. Variable energy costs, in turn, depend on the production volume that is processed per unit of time. Both types of energy consumption are illustrated in Figure 2. The fixed component is not affected by a change in the production rate or an increase in the volume of the warehouse, while the variable component increases as the production rate of the machine is increased.

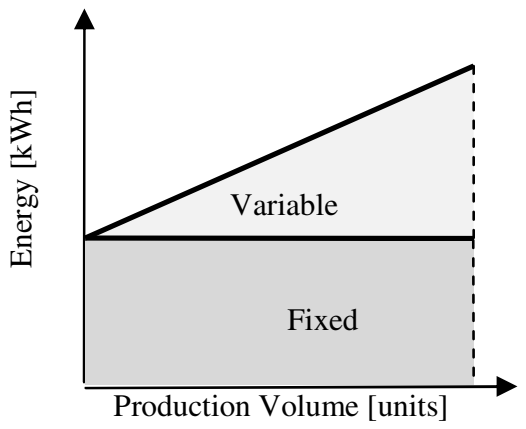

Fig. 2. Energy consumption as a function of the production volume

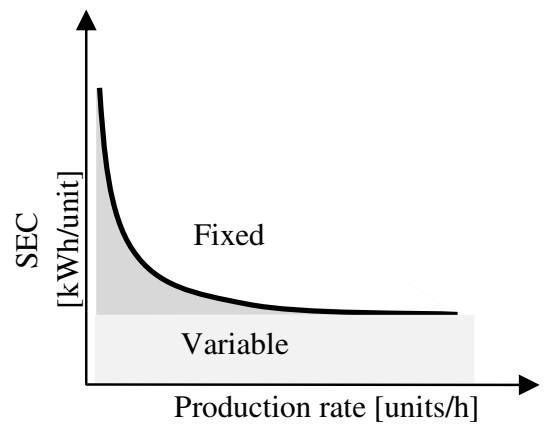

Fig. 3. Specific Energy Consumption as a function of the production rate

Figure 3 illustrates how energy consumption per unit of the product develops in the production rate. It can be seen that if we consider the Specific Energy Consumption (SEC) $[\mathrm{kWh} / \mathrm{kg}]$, the variable component remains constant for different production rates, while the fraction of the fixed component that is assigned to one unit of the product decreases as the production rate is increased.

A number of studies have been carried out to benchmark energy uses in warehouses [4]. Based on this empirical evidence, especially for refrigerated warehouses, the relationship between SEC and the volume of the warehouse can be modeled as in Figure 4. Thus, the SEC decreases both in the production rate as well as in the size of the warehouse.

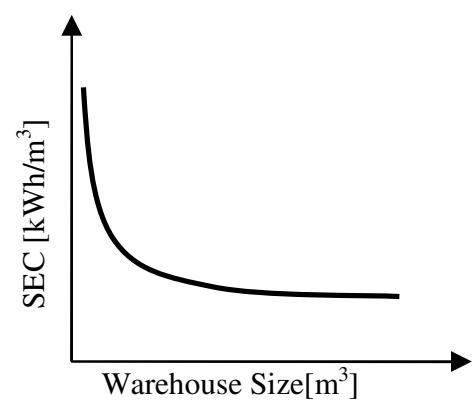

Fig. 4. Specific Energy Consumption as a function of the warehouse size 
In this work, the energy consumption of the production process and the warehouse are formulated with the help of the SEC, which is a well-accepted variable for measuring energy consumption and energy costs. All types of energy consumption, named $S E C_{V p}$ for the Specific Energy Consumption at the production line of the vendor, $S E C_{V_{w}}$ for the Specific Energy Consumption at the warehouse of the vendor and $S E C_{B w}$ for the Specific Energy Consumption at the warehouse of the buyer, are modeled as follows:

$$
\begin{gathered}
S E C_{V p}=a \cdot(p)^{-b} \\
S E C_{V w}=\alpha \cdot\left(q_{\max , v}(q, n)\right)^{-\beta} \\
S E C_{B w}=\gamma \cdot\left(q_{\max , b}(q)\right)^{-\delta}
\end{gathered}
$$

The maximum inventory at the vendor is $q_{\max , v}(q, n)=q \cdot n \cdot\left(1-\frac{D}{p}\right)$, while the maximum inventory at the buyer equals $q_{\max , b}(q)=q$.

Energy costs are calculated as the energy consumption of the production process, i.e. the Specific Energy Consumption multiplied with the demand and the energy cost $\left(\mathrm{EC}_{\mathrm{Vp}}\right)$, and the energy consumption of the warehouses, calculated as the Specific Energy Consumption multiplied with the maximum size of the warehouse and the energy cost $\left(\mathrm{EC}_{\mathrm{V}_{\mathrm{w}}}, \mathrm{EC}_{\mathrm{Bw}}\right)$, as in the following formula:

$$
\begin{gathered}
E C_{V p}=S E C_{V p} \cdot D \cdot e \\
E C_{V w}=S E C_{V w} \cdot q_{\max , v}(q, n) \cdot e \\
E C_{B w}=S E C_{B w} \cdot q_{\max , b}(q) \cdot e
\end{gathered}
$$

The total energy cost is the sum of the three components given in Eqs. (5) to (7):

$$
E C(q, n)=E C_{V p}+E C_{V w}+E C_{B w}
$$

If energy costs are considered in addition, the total costs are a function of the lot size and the number of shipments, and they are calculated as:

$$
\begin{gathered}
\operatorname{TC}(q, n)=\left(A_{1}+n \cdot A_{2}\right) \cdot \frac{D}{n \cdot q}+h_{1} \cdot\left(\frac{D \cdot q}{p}+\frac{(p-D) \cdot n \cdot q}{2 \cdot p}\right)+\left(h_{2}-h_{1}\right) \cdot \frac{q}{2}+a \\
\cdot p^{-b} \cdot D \cdot e+\alpha \cdot\left(Q \cdot\left(1-\frac{D}{p}\right)\right)^{-\beta+1} \cdot e+\gamma \cdot(q)^{-\delta+1} \cdot e .
\end{gathered}
$$

The optimal values that minimize $\operatorname{Tr} C(q, n)$ are $\left(q^{*}, n^{*}\right)$, while the optimal parameters that minimize $T C(q, n$,$) are \left(q^{* *}, n^{* *}\right)$. Since it is not possible to use the first order conditions to minimize Eq. (9), a numerical analysis is necessary to investigate the behavior of the system.

\section{$4 \quad$ Numerical Analysis}

To study the behavior of the model, we performed a numerical analysis to investigate how the model parameters influence the optimal solution of the energy model. 
We performed the numerical analysis for a company in the dairy sector of Parmesan production and aging. The high energy consumption in this sector is due to the conditioning of the warehouse, in which milk and cheese are stocked.

Table 1 summarizes the data that was used in the analysis.

Table 1. Data used in the numerical analysis

\begin{tabular}{|r|r|l|r|r|l|}
\hline Milk necessary & 14 & {$[1 / \mathrm{kg}$ cheese $]$} & $h_{2}=$ & 0.15 & {$[€ /$ ton year $]$} \\
\hline Weight & 8 & {$[\mathrm{~kg} /$ Cheese round $]$} & $\alpha=$ & 392.15 & \\
\hline Volume occupied & 30 & {$\left[\right.$ Cheese round $\left./ \mathrm{m}^{3}\right]$} & $\beta=$ & 0.256 & \\
\hline$p=$ & $2 \div 50 \cdot 10^{6}$ & {$[1 /$ year $]$} & $\gamma=$ & 392.15 & \\
\hline$D=$ & $2 \cdot 10^{6}$ & {$[1 /$ year $]$} & $\delta=$ & 0.256 & \\
\hline$A_{1}=$ & 2,000 & {$[€ /$ set-up $]$} & $a=$ & 25.354 & \\
\hline$A_{2}=$ & 400 & {$[€ /$ order $]$} & $b=$ & 0.29 & \\
\hline$h_{1}=$ & 0.1 & {$[€ /$ ton year $]$} & $e=$ & 0.12 & {$[€ / \mathrm{kWh}]$} \\
\hline
\end{tabular}

The results of traditional model (minimizing Eq. (1)) and the energy model (minimizing Eq. (9)) are summarized in Table 2.

Table 2. Results of the numerical analysis

\begin{tabular}{|c|c|c|c|c|c|c|c|}
\hline & $\begin{array}{c}\text { Q [kg } \\
\text { cheese] }\end{array}$ & $\begin{array}{c}\text { TC } \\
{[€ / \text { year] }}\end{array}$ & $\begin{array}{c}\text { TrC } \\
{[€ / \text { year] }}\end{array}$ & $\begin{array}{c}\text { EC } \\
{[€ / \text { year] }}\end{array}$ & $\begin{array}{c}\text { Energy } \\
\text { storage } \\
{[\text { TOE/ton] }}\end{array}$ & $\begin{array}{c}\text { Energy } \\
\text { production } \\
{[\text { TOE/ton] }}\end{array}$ & $\begin{array}{c}\text { Total } \\
\text { TOE/ton }\end{array}$ \\
\hline Min $\boldsymbol{T r} \boldsymbol{C}$ & 21,381 & 840,682 & 36,757 & 803,924 & 3.70 & 0.33 & 4.03 \\
\hline Min $\boldsymbol{T C}$ & 3,506 & 370,629 & 132,989 & 237,640 & 0.86 & 0.33 & 1.19 \\
\hline
\end{tabular}

The results illustrate that the proposed energy model leads to a higher profit than the traditional model which does not consider energy costs. The total costs and the energy costs are lower in the energy model than in the traditional model, even if inventory carrying costs are higher. Figure 5 illustrates the trends of the total costs and its two main components as functions of the lot size Q.

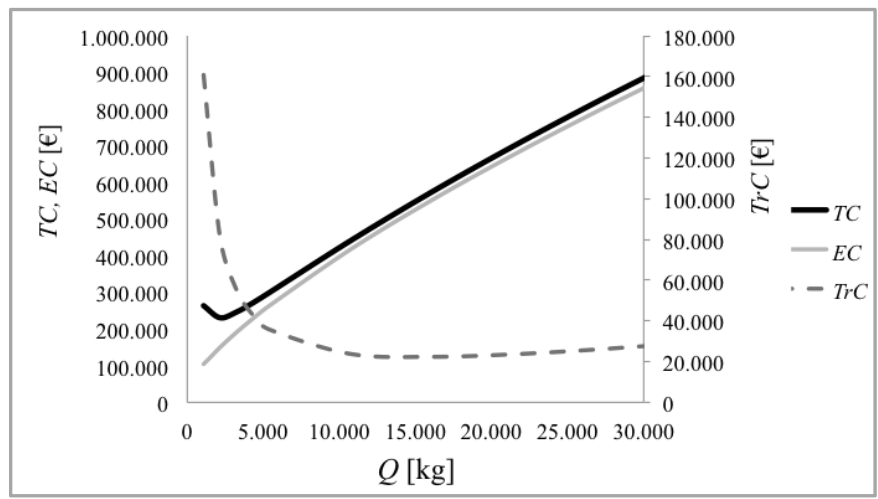

Fig. 5. Energy and traditional costs as functions of the lot size $Q$ 
Figure 6 illustrates the behavior of the two main cost components for varying production rates. As can be seen, the result is that both cost components $(E C$ and $\operatorname{Tr} C)$ increase in the production rate, but that the increase in $\operatorname{Tr} C$ costs (difference between dashed black line and dashed gray line) for the case where the optimal parameters considering energy consumption $\left(q^{* *}, n^{* *}\right)$ are used is much less than the decrease in $E C$ (difference between continuous black line and continuous gray line) while adopting the same parameters.

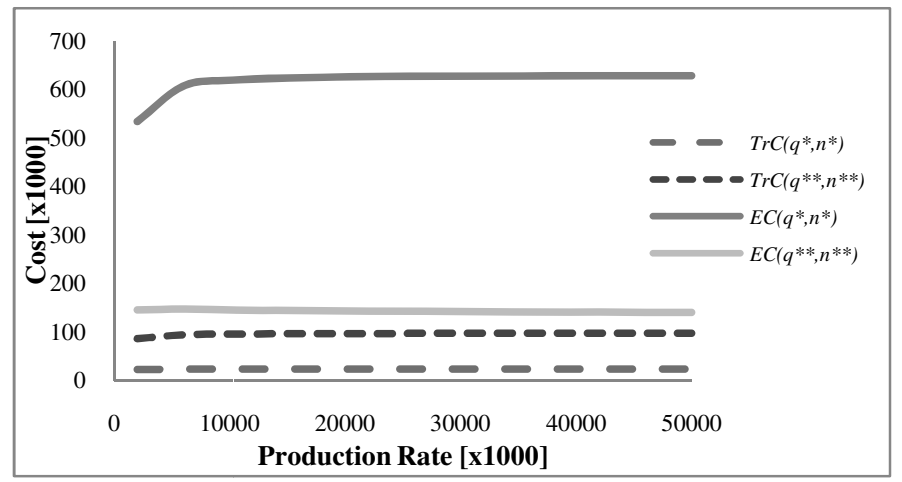

Fig. 6. Energy and inventory costs for the cases where the optimal parameters of the traditional model and the optimal parameters of the proposed energy model are adopted

Figure 7 illustrates the trend of the total Specific Energy Consumption, the specific consumption of energy by the warehouse and the Specific Energy Consumption of production as functions of the ratio of the demand and the production rate $(D / P)$.

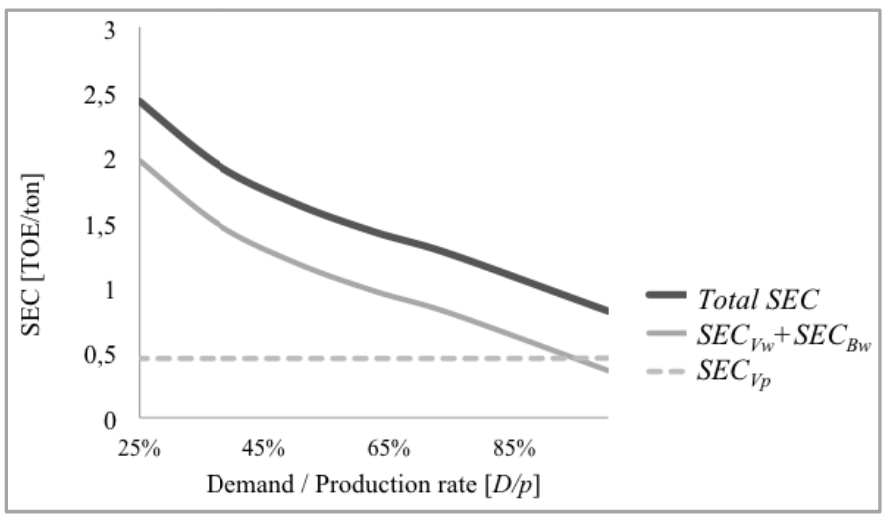

Fig. 7. Specific Energy Consumptions as functions of the ratio of the demand and the production rate 


\section{Conclusion}

This study proposed a variation of the traditional single-vendor single-buyer production inventory model by considering energy cost components for production and for warehousing of items (at the vendor and at the buyer). To model these cost components, we used specific relationships that were found in empirical studies. In particular, the production rate mainly affects the specific energy consumed during the production process, while the size of the warehouse (which is a result of the batch sizing policy) mainly affects the specific energy consumed for properly storing the items at the vendor and at the buyer.

The main finding of the study is that it is possible to reduce total costs while accounting for energy components and to obtain consistent saving in energy components, while only a small increase in traditional inventory carrying costs has to be accepted. Moreover, the results of this study are particularly important for energyintensive production processes in which the production rate may be set to a particularly high value.

This study has several limitations. First, it considered a very specific functional relationship to model the impact of the production rate on energy consumption. Other studies have shown that a varying production rate leads to a different pattern of resource consumption [6-7], and this may be valid for energy consumption as well. It is obvious that if a different functional relationship is assumed, the results of the model may change. Secondly, this study did not take account of all processes in a supply chain that consume energy (e.g. in [8] the effect on lot sizing decisions of different temperature settings in a cold supply chain is studied). Accomplishing these two and other aspects in an extension of this paper would be helpful to further our understanding of the impact of energy consumption and energy costs on the production and distribution policies of supply chains.

\section{References}

1. Glock, C.H.: The joint economic lot size problem: A review. International Journal of Production Economics 135, 671-686 (2012)

2. Bettoni, L., Zanoni, S.: Energy implications of production planning decisions. In: Frick, J., Laugen, B.T. (eds.) Advances in Production Management Systems. IFIP AICT, vol. 384, pp. 9-17. Springer, Heidelberg (2012)

3. Gutowski, T., Dahmus, J., Thiriez, A.: Electrical Energy Requirements for Manufacturing Processes. In: 13th CIRP International Conference on Life Cycle Engineering, Leuven (2006)

4. DEFRA, Greenhouse Gas Impacts of Food Retailing: Final Report (2008), http://statistics.defra.gov.uk/esg/reports/

5. Hill, R.M.: The single-vendor single-buyer integrated production-inventory model with a generalised policy. European Journal of Operational Research 97, 493-499 (1997)

6. Glock, C.H.: Batch sizing with controllable production rates. International Journal of Production Research 48, 5925-5942 (2010)

7. Glock, C.H.: Batch sizing with controllable production rates in a multi-stage production system. International Journal of Production Research 49, 6071-6039 (2011)

8. Zanoni, S., Zavanella, L.: Chilled or frozen? Decision strategies for sustainable food supply chains. International Journal of Production Economics 140(2), 731-736 (2012) 